Article

\title{
Improving Colloidal Stability of Sepiolite Suspensions: Effect of the Mechanical Disperser and Chemical Dispersant
}

\author{
Luís Alves $^{1, *(\mathbb{D})}$, Eduardo Ferraz ${ }^{2,3}\left(\mathbb{D}\right.$, Julio Santarén ${ }^{4}\left(\mathbb{D}\right.$, Maria G. Rasteiro $^{1}$ (D) \\ and José A. F. Gamelas ${ }^{1, *(D)}$ \\ 1 Department of Chemical Engineering, University of Coimbra, CIEPQPF, Rua Sílvio Lima, Pólo II, \\ PT-3030-790 Coimbra, Portugal; mgr@eq.uc.pt \\ 2 Techn \& Art, Polytechnic Institute of Tomar, Quinta do Contador, Estrada da Serra, \\ PT-2300-313 Tomar, Portugal; ejmoferraz@ipt.pt \\ 3 Geobiotec, Geosciences Department, Campus Universitário de Santiago, University of Aveiro, \\ PT-3810-193 Aveiro, Portugal \\ 4 Tolsa, SA, Research \& Technology for New Businesses, Ctra. de Madrid a Rivas Jarama, 35, \\ ES-28031 Madrid, Spain; jsantaren@tolsa.com \\ * Correspondence: luisalves@ci.uc.pt (L.A.); jafgas@eq.uc.pt (J.A.F.G.)
}

Received: 31 July 2020; Accepted: 28 August 2020; Published: 2 September 2020

\begin{abstract}
To allow the use of fibrous-like clays, as sepiolite, in different applications, their disaggregation and the formation of stable suspensions are crucial steps to enhance their performance significantly, e.g., in cellulose nanofibrils/clay composite formulations, enabling an adequate mixture of the matrix and filler individual components. Three distinct physical treatments of dispersion (magnetic stirring, high-speed shearing, and ultrasonication) and four different chemical dispersants (polyacrylate, polyphosphate, carboxymethylcellulose, and alginate, all in the form of sodium salts) were tested to improve the dispersibility and the formation of stable suspensions of sepiolite. Two sepiolite samples from the same origin but with different pre-treatments were evaluated. The particle size and suspension stability were evaluated by dynamic light scattering, zeta potential measurements and optical microscopy. Additionally, the sepiolite samples were initially characterized for their mineralogical, chemical, and morphologic properties. Of the three physical dispersion treatments tested, the ultrasonicator typically produced more stable suspensions; on the other hand, the biopolymer carboxymethylcellulose showed a higher ability to produce stable suspensions, being, however, a smaller particle size obtained when polyphosphate was used. Remarkably, 47 out of 90 prepared suspensions of sepiolite stayed homogeneous for at least three months after their preparation. In sum, the combination of a high energy dispersing equipment with an appropriate dispersing agent led to stable suspensions with optimal properties to be used in different applications, like in the composite production.
\end{abstract}

Keywords: fibrous clay; dispersion; organic-inorganic hybrid; bionanocomposite

\section{Introduction}

Sepiolite is a natural fibrous clay with the ideal formula $\mathrm{Si}_{12} \mathrm{O}_{30} \mathrm{Mg}_{8}(\mathrm{OH})_{4}\left(\mathrm{OH}_{2}\right)_{4} \cdot 8 \mathrm{H}_{2} \mathrm{O}$. The structure of this magnesium silicate is based on structural blocks alternating with structural cavities, called tunnels, which gives rise to a highly porous framework. The structural blocks comprise two tetrahedral silica sheets, with the tetrahedra inverted from one sheet to the other, sandwiching a central octahedral sheet of magnesium oxide-hydroxide. In the octahedral sheet, both hydroxyl ions and water molecules are coordinated to magnesium centers, while the remaining water molecules occupy 
positions inside the tunnels. The presence of tunnels with cross-section dimensions of $1.06 \times 0.37$ $\mathrm{nm}^{2}$ [1] enables the retention of small organic molecules. Isomorphic substitutions of $\mathrm{Si}^{4+} \mathrm{by}^{2 l^{3+}}$ in the tetrahedral layer or $\mathrm{Mg}^{2+}$ by $\mathrm{Al}^{3+}$ in the octahedral layer promote the formation of charged sites in the structure. An important characteristic of this mineral is the high density of silanol groups on the particle surface, much higher than that of platelet-like clay minerals. These are formed from the bonding between non-shared oxygens from the tetrahedral silica sheets located on channels (tunnels at the surface of the particle) and hydrogen [2].

Galán (1996) collected classical applications (sorptive, catalytic, organo-mineral derivatives, rheological, filler, animal nutrition, biomaterials, and environmental) for the use of sepiolite [3]. Other uses of sepiolite, like foams, films, supported lipid membrane, hybrid bilayers, other types of supported membranes, bioplastics and membranes, drug delivery, DNA non-viral transfection, vaccines, tissue engineering and scaffolds, environmental applications, bionanocomposites as source of supported carbonaceous materials and bionanocomposites as components of sensor devices and bioreactors, have been developed [4].

As stated previously [5], a good dispersion of the clay mineral in a selected medium, preferentially water-based, is essential to achieve superior properties in the final bionanocomposites. Acicular individual particles of fibrous clays, such as sepiolite, easily aggregate in water by hydrogen bonding and Van der Waals interactions to form bundles and aggregates, which limits the quality of the clay dispersion [6]. Additionally, the characteristic crystalline structure of fibrous clays does not allow them to be delaminated (or exfoliated) as in the case of the plate-like clays. To improve the dispersibility of sepiolite, several strategies have been evaluated and the most common approaches are as follows: mechanical treatment; addition of chemical dispersants to the suspension; chemical modification of the mineral surface.

The mechanical treatment may consist of ultrasonication or high-speed shearing processes, among others, able to disrupt the bulk bundles into smaller bundles or single rods, without damaging the crystal structure and length of nanorods. Ultrasonication has been presented as a relatively simple approach to disaggregate sepiolite fibers and enhance their characteristic properties, which is not possible to be accomplished by magnetic stirring only. For instance, when a sepiolite suspension in water was previously submitted to ultrasonication, under adjusted conditions, the specific surface area was found to increase from 322 to $487 \mathrm{~m}^{2} \cdot \mathrm{g}^{-1}$, which improved its adsorption capacity of methylene blue dye [7]. Ultrasonication has also been used as a method to generate homogeneous and stable dispersions with other materials in water for the preparation of hybrid and composite structures $[8,9]$. It was claimed that high energy ultrasonication can also promote the formation of thixotropic gels with highly dispersed fibrous clays, although with shorter fibers [3]. On the other hand, Viseras et al. (1999) used high-speed homogenization to disperse colloidal particles of sepiolite [10]. Rotor speed of $8000 \mathrm{rpm}$ for a period of $10 \mathrm{~min}$ was used to enhance the viscosity of the suspension and to produce a stable dispersion. High-pressure homogenization can also be an interesting approach to disaggregate sepiolite particles in water suspensions, as it was reported for palygorskite [11].

The addition of chemical dispersants is also used to stabilize the dispersions of fibrous clays. By changing the surface characteristics of the individual particles (rods) of the fibrous clay, namely their charge and surface chemistry, they may contribute to a better dispersion without damaging the crystal structure. The choice of the dispersant is crucial for the target result. Takei et al. (2013) have evaluated the effect of the addition of different types of dispersants (followed by ultrasonication) to disperse sepiolite on the tensile strength of composites produced with nitrile butadiene rubber; they found that ammonium polycarboxylate and amino alcohol polyphosphate, in particular, provided valuable results, as evaluated by the increase in tensile strength of the sepiolite-rubber composite [12]. More recently, ionic liquids have also been used to disperse sepiolite [13]. The use of ionic liquids was found to influence the arrangement of sepiolite particles, as well as the thermal properties but without significant structural changes of it. 
The chemical modification of the surface has also been presented as a viable approach to improve the dispersion of fibrous clays. It has been found that modification of sepiolite fibers by reaction with methyltrimethoxysilane (MTMS) in water, at appropriate concentrations, enhanced the dispersion of the aggregates or large bundles of fibers as almost individual nanorods forming aqueous gels. The surface of the fibers becomes covered with nanometric MTMS condensed spheres, which, according to the authors, reduces strongly the contact surface between fibers and precludes a strong reaggregation of the material [14].

The present work evaluates the influence of four dispersing agents (sodium polyphosphate, hydrophobically modified poly(sodium acrylate) (HM-PAA), sodium carboxymethylcellulose (CMC), and sodium alginate) and three distinct dispersion apparatus (magnetic stirring, ultrasonication, and high-speed shearing) on the dispersion state of water-based suspensions of sepiolite, at low concentration. The capacity of each dispersing agent and apparatus, as well as the effect of the suspension $\mathrm{pH}$, were studied aiming at improving the disaggregation and the formation of stable suspensions, i.e., no phase separation (by visual inspection) for a period of at least 90 days, crucial to significantly enhance the performance and extend the application of fibrous-like clays, for example, in cellulose nanofibrils/clay composite formulations, allowing an adequate mixture of the matrix and filler individual components [5]. Related with the chemical dispersants addressed in the present work, and polysaccharides, in general, studies have been reported in literature dealing with the preparation of composites of sepiolite with poly(sodium acrylate) [15], CMC and alginate (films) [16], alginate and starch (foams) [17], and nanofibrillated cellulose (nanopapers) [18]. However, none of the works reported a comprehensive and systematic study of the effect of the biopolymers and/or synthetic polymers over the dispersion and stability of the fibrous clay suspensions.

\section{Materials and Methods}

\subsection{Clays and Chemicals}

In this study, two natural sepiolite samples, referred as sepiolite 1 and sepiolite 2, from the deposit of Vallecas-Vicálvaro (Madrid, Spain), supplied by Tolsa, SA (Madrid, Spain) were used. Sepiolite 1 was processed by a dry micronization process using a jet mill to break the fiber bundles down into micron-size particles. Sepiolite 2 was micronized using a wet process that produces an extensive deagglomeration of the sepiolite fiber bundles without affecting their aspect ratio [19].

Hydrochloric acid (Puriss p.a., ACS reagent grade, fuming, 37\%) was acquired from Fluka, Porto Salvo, Portugal. Sodium hydroxide (reagent grade, $\geq 98 \%$, pellets) was purchased from Sigma-Aldrich (Merck), Algés, Portugal. The dispersing agents used were sodium polyphosphate (Emplura grade, 99\%, catalogue number 106529) purchased from Sigma-Aldrich (Merck); hydrophobically modified poly(sodium acrylate) (HM-PAA) (Acusol 820, 30\% active emulsion polymer consisting of 40\% methacrylic acid, $50 \%$ ethyl acrylate, and $10 \%$ stearyl oxypoly ethyl methacrylate; the viscosity of an aqueous solution containing $1 \%(w / w)$ polymer at $\mathrm{pH} 7$ is ca. $12 \mathrm{~Pa} \cdot \mathrm{s})$ acquired from Rohm and Haas, Philadelphia, PA, USA; carboxymethylcellulose sodium salt (molecular weight of $250 \mathrm{kDa}$, degree of substitution of 0.7) and alginic acid sodium salt from brown algae (Bioreagent, suitable for immobilization of micro-organisms, catalogue number 71238) obtained from Sigma-Aldrich (Merck). The estimated molecular weight of alginate was ca. $280 \mathrm{kDa}$ (by rheometry) and ca. $210 \mathrm{kDa}$ (by capillary viscometry). All chemicals were used as received without any further purification.

\subsection{Characterization of the Sepiolite Samples}

The samples were analyzed according to mineralogical, physical, and chemical characterization, using the following equipment and operational conditions.

The mineralogical characterization obtained by powder $X$-ray diffraction was carried out using a Philips X'Pert MPD diffractometer (Amsterdam, The Netherlands), with CoK $\alpha$ radiation $(\lambda=1.7903$ $\AA)$, at a current of $35 \mathrm{~mA}$ and a voltage of $40 \mathrm{kV}$. Diffractograms were collected by the counting 
method (step $0.025^{\circ}$ and time $1.0 \mathrm{~s}$ ) in the $2 \theta$ range of $5-60^{\circ}$. Crystalline phases were discriminated by comparison with reference diffractograms from the International Centre for Diffraction Data.

The chemical composition of the sepiolite samples was determined by X-ray fluorescence using a PANalytical equipment PW 4400/40 Axios with CrK $\alpha$ radiation (Malvern Panalytical, Almelo, The Netherlands). The Loss on Ignition (LOI) was determined gravimetrically, by treatment at $1000{ }^{\circ} \mathrm{C}$ for $2 \mathrm{~h}$ in a Nabertherm laboratory furnace.

FTIR-ATR spectra of the minerals were obtained on a JASCO FT/IR-4200 spectrometer (JASCO, Tokyo, Japan) using a MKII Golden Gate accessory. The spectra were recorded in the $800-4000 \mathrm{~cm}^{-1}$ range with a resolution of $4 \mathrm{~cm}^{-1}$ and 64 scans.

Thermal analysis was done using a simultaneous DSC-TGA thermal analyzer (TA Instrument SDT Q600, New Castle, DE, USA). The samples were heated from room temperature up to $1000{ }^{\circ} \mathrm{C}$, at a rate of $10{ }^{\circ} \mathrm{C} / \mathrm{min}$, under a nitrogen atmosphere.

Brunauer, Emmett, and Teller (BET) specific surface area was determined by nitrogen adsorption at $77 \mathrm{~K}$ using a Micromeritics Gemini V analyzer (Micromeritics Instrument, Norcross, GA, USA). The samples were previously degassed at $124{ }^{\circ} \mathrm{C}$ under nitrogen flow for $12 \mathrm{~h}$.

Particle size distribution was determined in the $0.01-3500 \mu \mathrm{m}$ range using a laser diffraction particle size analyzer Malvern Mastersizer 3000 (Malvern Instruments, Malvern, UK). The samples were previously dispersed in water in an automated dispersion unit Malvern Hydro LV, using $0.1 \mathrm{wt} \%$ tetrasodium pyrophosphate as dispersant.

The morphology of the particles was evaluated by field emission scanning electron microscopy (FE-SEM) in a Carl Zeiss Merlin-61-50 microscope ( Carl Zeiss, Oberkochen, Germany). Secondary electron mode and acceleration voltage of $1 \mathrm{kV}$ were the operational conditions. The samples were previously sputter-coated with a thin film of $\mathrm{Au} / \mathrm{Pd}$.

\subsection{Preparation of the Sepiolite Suspensions with Different Mechanical Dispersers and Chemical Dispersants}

Suspensions with $1.0 \mathrm{wt} \%$ of sepiolite were prepared at room temperature from their respective dry powders. The desired amount of clay powder was added into distilled water and the mixture stirred using a magnetic stirrer at $200 \mathrm{rpm}$; right after, the dispersing agents were added at a concentration of $0.1 \mathrm{wt} \%$, under constant mixing. Then, the suspensions were finished using different mixing systems: magnetic stirrer at $300 \mathrm{rpm}$ for $20 \mathrm{~min}$; high-shear disperser (Dispermat CV3-PLUS-E, VMA-Getzman $\mathrm{GmbH}$, Reichshof, Germany) at $5000 \mathrm{rpm}$ for $15 \mathrm{~min}$; ultrasound probe (Vibra-cell VC 505, Sonics, Newtown, CT, USA) working at $60 \%$ amplitude and $1 \mathrm{~s}$ pulse, for $10 \mathrm{~min}$. The $\mathrm{pH}$ of the suspensions was measured and for some cases adjusted to 3 (using $\mathrm{HCl} 1 \mathrm{M}$ ) or to 12 (using $\mathrm{NaOH} 1 \mathrm{M}$ ), after which, the suspensions were allowed to continue the mixture until the above referred times. Then, the suspensions were left stabilizing for particle size and zeta potential measurements, as well as before the microscopic analysis. The suspension stability was evaluated for a period of 90 days.

\subsection{Characterization of the Sepiolite Suspensions}

Zeta potential measurements of aqueous suspensions of the two mineral samples, at different $\mathrm{pH}$ values, were carried out in a Zetasizer NanoZS equipment (ZN 3500, Malvern Instruments, Malvern, UK) by electrophoretic light scattering. For this characterization, previously to the measurements, an aqueous suspension of the mineral sample $(2 \%, w / v)$ was magnetically stirred for $30 \mathrm{~min}$ at 500 $\mathrm{rpm}$. The zeta potential of this suspension with a $\mathrm{pH}$ of ca. 8.5 was measured. Then, the $\mathrm{pH}$ was adjusted to lower values by the addition of $\mathrm{HCl}$ (acidic series) or to higher values by the addition of $\mathrm{NaOH}$ (alkaline series). The suspension was always kept stirred between the measurements at different $\mathrm{pH}$ values. Measurements were done by taking the average of six repetitions. Different series of measurements were performed in order to check reproducibility of the results.

For the characterization of the mineral suspensions after the treatments referred in Section 2.3, the sepiolite suspensions at $1 \mathrm{wt} \%$ were diluted to $0.1 \mathrm{wt} \%$ using MilliQ water and transferred to the measurement cell before the measurements. 
To evaluate the size of the sepiolite particles in suspension, dynamic light scattering measurements were performed in the Zetasizer NanoZS equipment (ZN 3500, Malvern Instruments, Malvern, UK), with a $532 \mathrm{~nm}$ laser, using a backscatter angle detection of $173^{\circ}$, at $25^{\circ} \mathrm{C}$. Stable sepiolite suspensions with the concentration of $0.1 \mathrm{wt} \%$ were gently transferred to a glass cuvette and checked for the presence of bubbles. The average particle size (equivalent diameter) was determined from the distributions in intensity ( $\mathrm{Di}$ ) and based on six repetitions. The data optimized according to the non-negative least-squares (NNLS) algorithm and the polydispersity index (PDI) values were obtained through the Zetasizer Nano Software (version 7.11).

The dispersion/aggregation state of the sepiolite suspensions was evaluated using an Olympus BH-2 KPA microscope (Olympus Optical Co., Ltd., Tokyo, Japan) equipped with a high-resolution CCD color camera (Olympus ColorView III), at different $\mathrm{pH}$ values and using different dispersion agents and methods. Samples were kept between cover slips and illuminated with linearly polarized light and analyzed through a cross polarizer. Images were captured and analyzed using the analySIS software (Soft Imaging System GmbH, Münster, Germany).

\section{Results and Discussion}

\subsection{Characterization of the Sepiolite Samples}

The X-ray diffractograms of the two sepiolite samples were similar and indicated the presence of only sepiolite, pointing out to a clay with monomineralic composition (Figure 1).

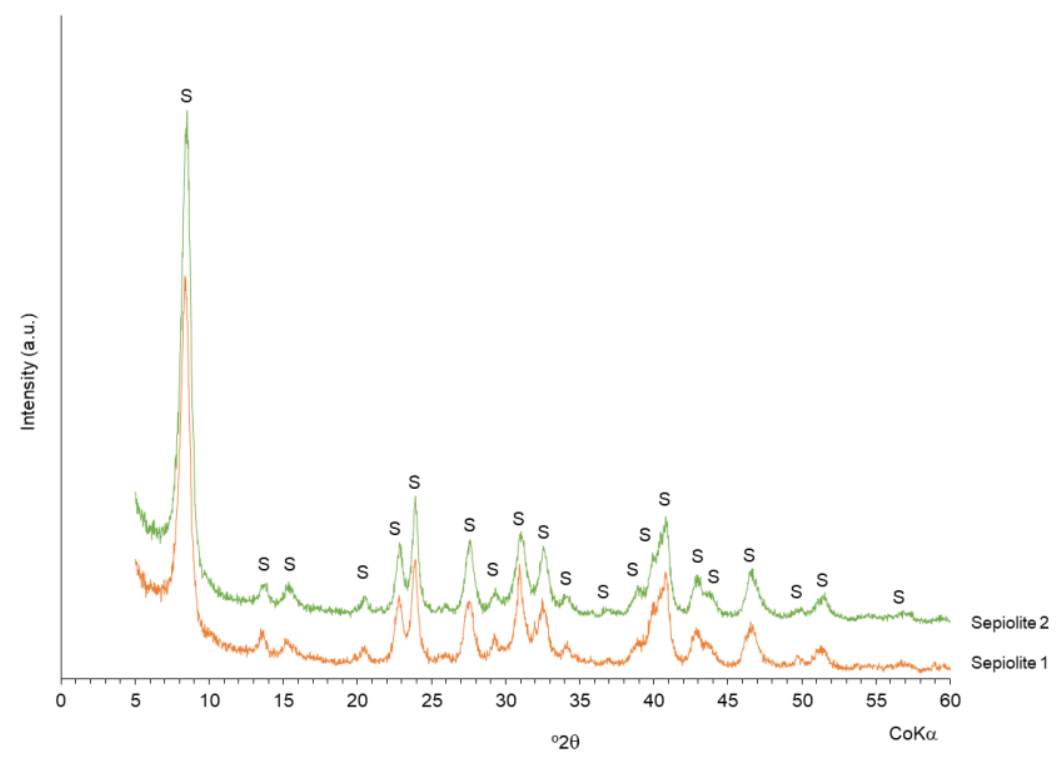

Figure 1. X-ray diffraction of the sepiolite samples with identification of the mineral phase.

Additionally, the chemical composition of the two sepiolite samples was also similar (Table 1). The high content of $\mathrm{Si}$ and $\mathrm{Mg}$ evidenced the magnesium silicate nature of these raw materials. The $\mathrm{SiO}_{2} / \mathrm{MgO}$ ratio was 2.41 for sepiolite 1 and 2.35 for sepiolite 2, which are common values for this type of mineral [20]. Al and Fe were found, which are known to substitute $\mathrm{Si}$ and $\mathrm{Mg}$ in the crystalline structure. The XRF data are in agreement with results provided by Sabah et al. (2007) for other sepiolite samples from the same origin [20]. 
Table 1. XRF data (in wt $\%$ ) of the sepiolite samples.

\begin{tabular}{ccc}
\hline & Sepiolite 1 & Sepiolite 2 \\
\hline $\mathrm{SiO}_{2}$ & 53.6 & 53.5 \\
$\mathrm{MgO}$ & 22.3 & 22.8 \\
$\mathrm{Al}_{2} \mathrm{O}_{3}$ & 2.10 & 1.93 \\
$\mathrm{CaO}$ & 0.28 & 0.17 \\
$\mathrm{Fe}_{2} \mathrm{O}_{3}$ & 0.56 & 0.58 \\
$\mathrm{Na}_{2} \mathrm{O}$ & 0.15 & 0.12 \\
$\mathrm{~K}_{2} \mathrm{O}$ & 0.67 & 0.51 \\
$\mathrm{MnO}$ & 0.02 & 0.02 \\
$\mathrm{TiO}_{2}$ & 0.11 & 0.07 \\
$\mathrm{P}_{2} \mathrm{O}_{5}$ & 0.03 & 0.04 \\
$\mathrm{SO}_{3}$ & 0.03 & 0.03 \\
$\mathrm{~F}^{-}$ & 0.78 & 0.97 \\
$\mathrm{LOI}^{\mathrm{a}}$ & 19.4 & 19.3 \\
\hline \multicolumn{3}{c}{}
\end{tabular}

The thermogravimetric analysis results of the two sepiolite samples were similar (Figure 2), in agreement with the similar chemical composition. The first and major endothermic weight loss $(\approx 11 \%)$ can be seen by increasing temperature up to ca. $100{ }^{\circ} \mathrm{C}$; this is mainly due to the release of zeolitic water and hygroscopic water. A second endothermic weight loss $(\approx 2.8-3.0 \%)$ is observed from ca. 100 to $280{ }^{\circ} \mathrm{C}$, attributed to release of some Mg-coordinated water. The release of the remaining $\mathrm{Mg}$-coordinated water is completed in a third stage, extending up to about $600{ }^{\circ} \mathrm{C}(\approx 2.8-3.1 \%)$. A final endothermic weight loss step from ca. 600 to $1000{ }^{\circ} \mathrm{C}(\approx 3.3-3.7 \%)$, occurs due to the dehydroxylation of the octahedrally coordinated hydroxyl groups [21-24]. The total thermogravimetric weight losses $(\approx 20 \%)$ are in agreement with the loss on ignition values (Table 1 ) presented above.

FTIR spectroscopy was also used to characterize the mineral (Figure 3). The spectra of the two sepiolite samples were quite similar. The bands at 3688 and $3616 \mathrm{~cm}^{-1}$ for sepiolite 1 and at 3685 and $3625 \mathrm{~cm}^{-1}$ for sepiolite 2 are associated to the stretching of the $\mathrm{OH}$ coordinated with $\mathrm{Mg}$ [25]. At 3557 and $3564 \mathrm{~cm}^{-1}$ for sepiolite 1 and sepiolite 2, respectively, a band occurs related with the $\mathrm{OH}$-stretching for water coordinated with $\mathrm{Mg}$ [25]. For both samples, the diffuse region between 3400 and $3200 \mathrm{~cm}^{-1}$ may include bands attributed to adsorbed, zeolitic, and coordinated water. In the $2370-2330 \mathrm{~cm}^{-1}$ region, bands corresponding to ambient $\mathrm{CO}_{2}$ are present. A group of bands related to $\mathrm{OH}$ bending are observed at 1660 (for sepiolite 1 ) and $1666 \mathrm{~cm}^{-1}$ (for sepiolite 2) assigned to water strongly bonded to $\mathrm{Mg}$ [25]; 1649 (sepiolite 1) and $1652 \mathrm{~cm}^{-1}$ (sepiolite 2) related to zeolitic water [26]; 1636 (sepiolite 1) and $1634 \mathrm{~cm}^{-1}$ (sepiolite 2) attributed to adsorbed water [26]. Bands at 1210, 1070 (shoulder), and 1000 $\mathrm{cm}^{-1}$ in the case of sepiolite 1 and at 1209, 1078 (shoulder), and $1003 \mathrm{~cm}^{-1}$ in the case of sepiolite 2 were assigned to $\mathrm{Si}-\mathrm{O}$ stretching modes, whereas those at 969 (sepiolite 1) and $973 \mathrm{~cm}^{-1}$ (sepiolite 2) were attributed to $\mathrm{OH}$ deformation in the $\mathrm{Mg}-\mathrm{OH}$ or $\mathrm{Al}-\mathrm{OH}$ bonds [25]. 

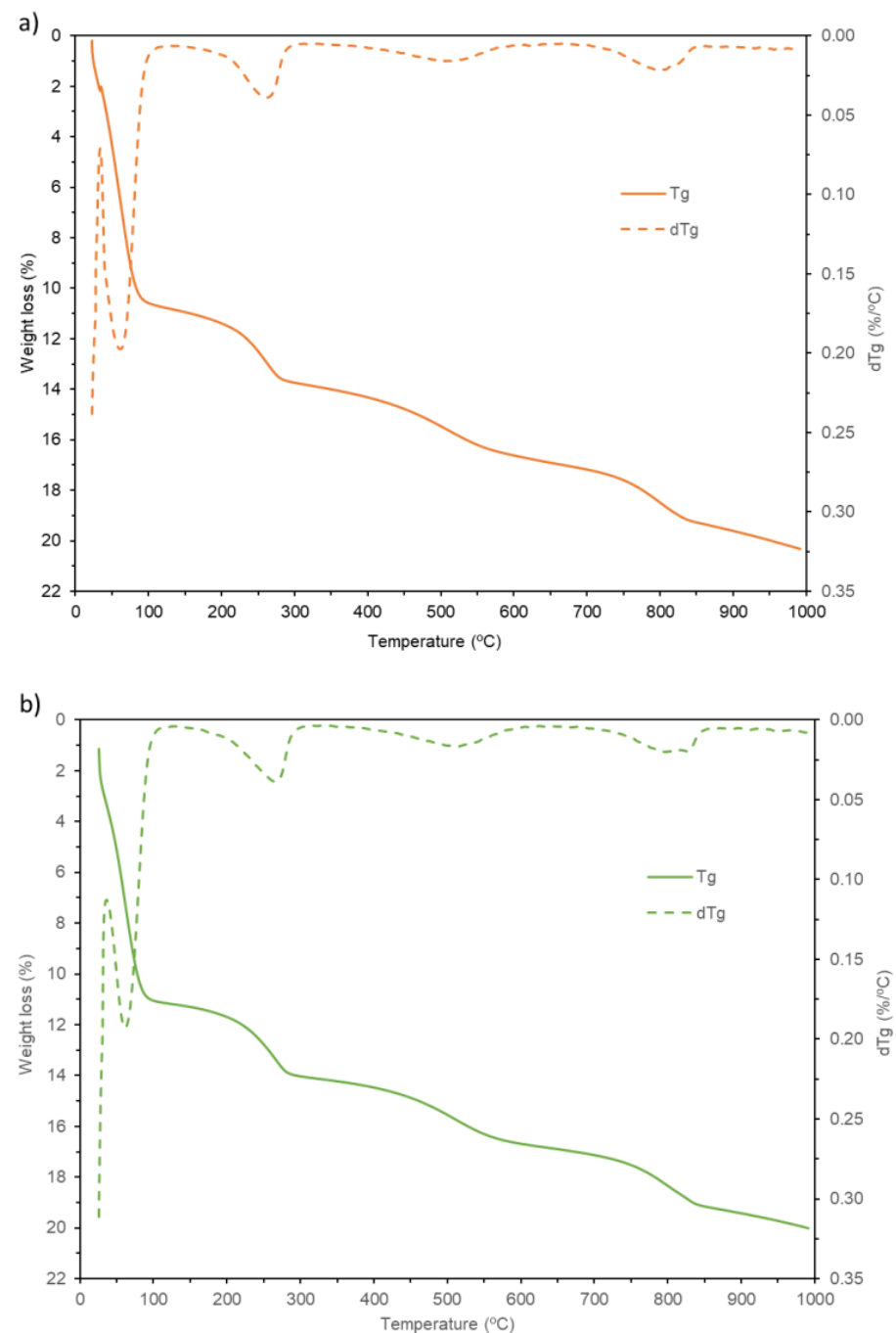

Figure 2. Thermogravimetry (solid) and derivative (dashed) curves of the sepiolite samples: (a) sepiolite 1 ; (b) sepiolite 2.

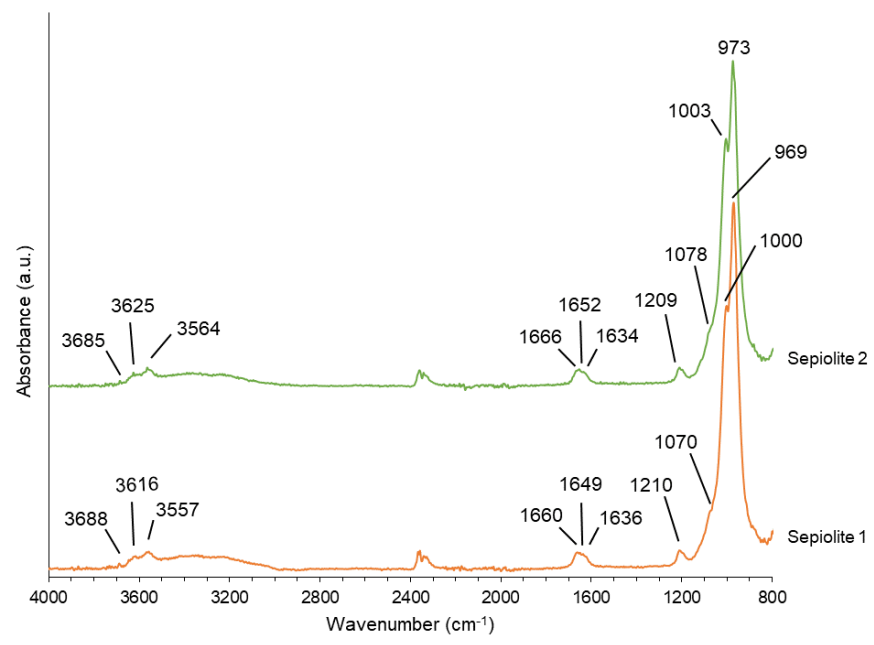

Figure 3. FTIR spectra of the sepiolite samples. 
Some physical parameters of the sepiolite samples were also determined, namely particle sizes and specific surface area. The results are summarized in Table 2. Considering the results supplied by the manufacturing company, similar Dv10 and Dv50 size values are obtained for the two sepiolites; the apparent larger Dv90 of sepiolite 2 compared to sepiolite 1 is due to the presence of a few agglomerates with bigger dimensions in sepiolite 2 dispersion. The original materials, as supplied by Tolsa, did not undergo any optimized dispersion procedure for these measurements, being the starting point for the developed work discussed in Section 3.2. Thus, the size values shown in Table 2 correspond for sure to aggregated particles, and this state of the initial materials is, in our opinion, the reason for the formation of suspensions of poor stability. The more extensive disentanglement of the fiber bundles in sepiolite 2 compared to sepiolite 1 makes the surface more available and it results in a higher specific surface area.

Table 2. Physical data of the sepiolite samples.

\begin{tabular}{lccccc}
\hline & \multicolumn{3}{c}{ Particle Size Distribution ${ }^{\mathbf{a}}(\boldsymbol{\mu m})$} & \multirow{2}{*}{ SSA $^{\mathbf{b}}\left(\mathbf{m}^{2} / \mathbf{g}\right)$} \\
\cline { 2 - 5 } & Dv (4,3) & Dv10 & Dv50 & Dv90 & \\
\hline Sepiolite 1 & 12.3 & 3.3 & 9.4 & 24.7 & 288 \\
Sepiolite 2 & 17.0 & 3.0 & 9.6 & 31.1 & 337 \\
\hline
\end{tabular}

a Dv10, Dv50, and Dv90 are the equivalent diameters corresponding to $10 \%, 50 \%$, and $90 \%$, respectively, of the cumulative undersize particle size distribution (volume-weighted); Dv $(4,3)$ is the weighted mean value of particle size by volume. ${ }^{\mathrm{b}}$ SSA-specific surface area.

The SEM microphotographs clearly showed the fibrous nature of the studied samples, composed by bundles, and individual long rods with thin diameter. No contaminants were detected in the samples (Figure 4).
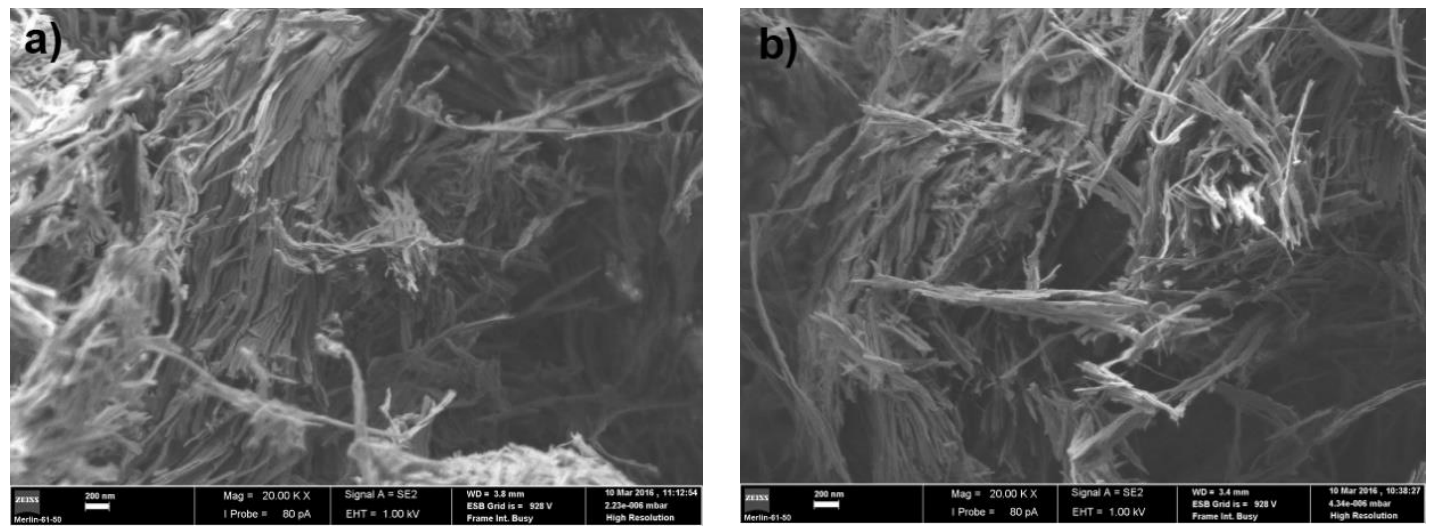

Figure 4. FE-SEM micrographs of the sepiolite samples at 20,000 magnification: (a) sepiolite 1; (b) sepiolite 2. The scale bars correspond to $200 \mathrm{~nm}$.

Zeta potential results for aqueous suspensions of clay are shown in Figure 5. For sepiolite 1, zeta potential at the initial $\mathrm{pH}(\approx 8.5)$ is negative (ca. $-12 \mathrm{mV})$ and tended to increase (in absolute value) with the increase of $\mathrm{pH}$. Increasing $\mathrm{pH}$ until 12 highly increased the zeta potential to around $-45 \mathrm{mV}$. On the other hand, zeta potential varied less in the region of $\mathrm{pH} 8.5$ down to $\mathrm{pH}$ 3.0. At $\mathrm{pH}$ 3.7, the zeta potential was $-3 \mathrm{mV}$. The isoelectric point was found at a $\mathrm{pH}$ value of 3.2-3.3. Under this condition, there was an equilibrium between positive and negative charges on the surface of sepiolite particles. The isoelectric point found for this sample is similar to that determined for a sample of similar origin, for which the authors determined an isoelectric point $\mathrm{pH}$ of ca. 3.4, at the same mineral content [20]. For $\mathrm{pH} 2.6$, the zeta potential achieved a relatively high positive value $(+9 \mathrm{mV})$. The variation of zeta potential with $\mathrm{pH}$ is the expected for this type of mineral and can be rationalized in terms of the acid-base behavior of the surface hydroxyl groups $(\mathrm{M}-\mathrm{OH})$ of sepiolite. At $\mathrm{pH}$ values superior to the 
isoelectric point, the hydroxyl groups deprotonate releasing protons and forming negatively charged $\mathrm{M}-\mathrm{O}^{-}$species, providing a negative zeta potential. At $\mathrm{pH}$ values lower than the isoelectric point, they protonate to form $\mathrm{M}-\mathrm{OH}_{2}{ }^{+}$species, providing positive zeta potential. In the isoelectric point, the concentration of $\mathrm{M}-\mathrm{O}^{-}$and $\mathrm{M}-\mathrm{OH}_{2}{ }^{+}$is the same. Different isoelectric point values can be obtained depending on the sepiolite origin $[27,28]$. The presence of contaminants and defects in the crystalline structure of the sepiolite (e.g., isomorphic tetrahedral and octahedral substitutions) highly influence the $\mathrm{pH}$ value for the isoelectric point.

For sepiolite 2, the zeta potential results evidenced a trend similar to that found for sepiolite 1 (Figure 5). However, the values achieved at each $\mathrm{pH}$ are somewhat different. At $\mathrm{pH} 8.5$, the zeta potential was ca. $-20 \mathrm{mV}$ and increasing the $\mathrm{pH}$ till 12 increased it (in absolute value) to $-56 \mathrm{mV}$. At $\mathrm{pH}$ 3.0, zeta potential was $-4 \mathrm{mV}$. The isoelectric point was found to be at a $\mathrm{pH}$ near 2.5. At $\mathrm{pH} 1.6$, zeta potential was $+5 \mathrm{mV}$. Thus, in comparison to sepiolite 1, sepiolite 2 showed more negative values of zeta potential for the same $\mathrm{pH}$ and lower $\mathrm{pH}$ value for the isoelectric point. Since sepiolite 1 and 2 have similar mineralogical, chemical, and thermal properties, as demonstrated above, the different zeta potential values can be related to slightly different surface characteristics. The higher specific surface area of sepiolite 2 (Table 2) affords a higher exposure of silanol groups on the external surface of the particles which generates more negative values of zeta potential.
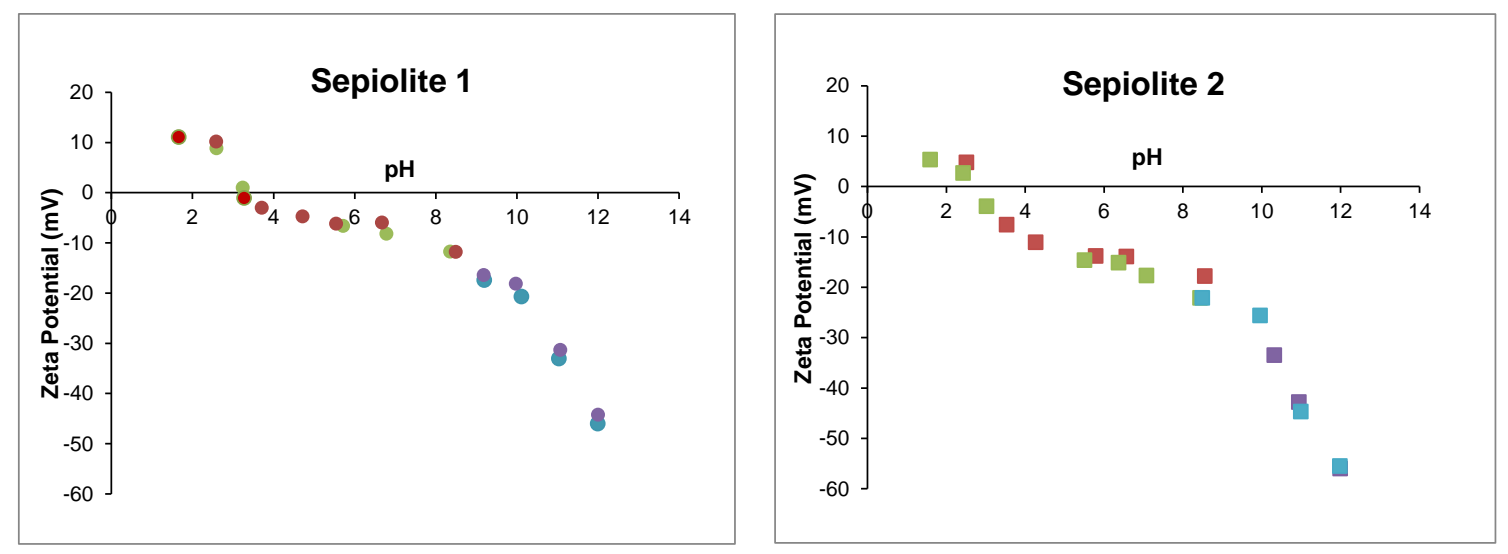

Figure 5. Zeta potential as a function of $\mathrm{pH}$ for the sepiolite 1 and sepiolite 2 samples (different series of measurements were performed, each one shown by a different color).

\subsection{Characterization of the Sepiolite Suspensions: Effects of Dispersing Equipment and Dispersant}

Images of the formed suspensions of sepiolite 1 and sepiolite 2 (at the natural $\mathrm{pH}$ of the suspensions), in the presence of sodium polyphosphate and without addition of dispersing agent, using different dispersing equipment, are presented in Figure 6.

As can be macroscopically observed, the use of sepiolite 2 resulted, overall, in suspensions of better stability, being only observed phase separation for the samples produced using the magnetic stirrer and a slight sedimentation of clay particles for the sample produced with the high-speed disperser. All the other three samples appeared stable for a long period of time, 90 days. Less stable suspensions were formed when sepiolite 1 was used, being only observed macroscopically uniform samples with the use of the sonicator as dispersion equipment. This is certainly related with the different pre-treatments used to prepare the two samples of sepiolite; the pre-treatment used to produce sepiolite 2 allows a better and slightly easier dispersion of the clay individual fibers, even if these have a longer length compared to sepiolite 1. 


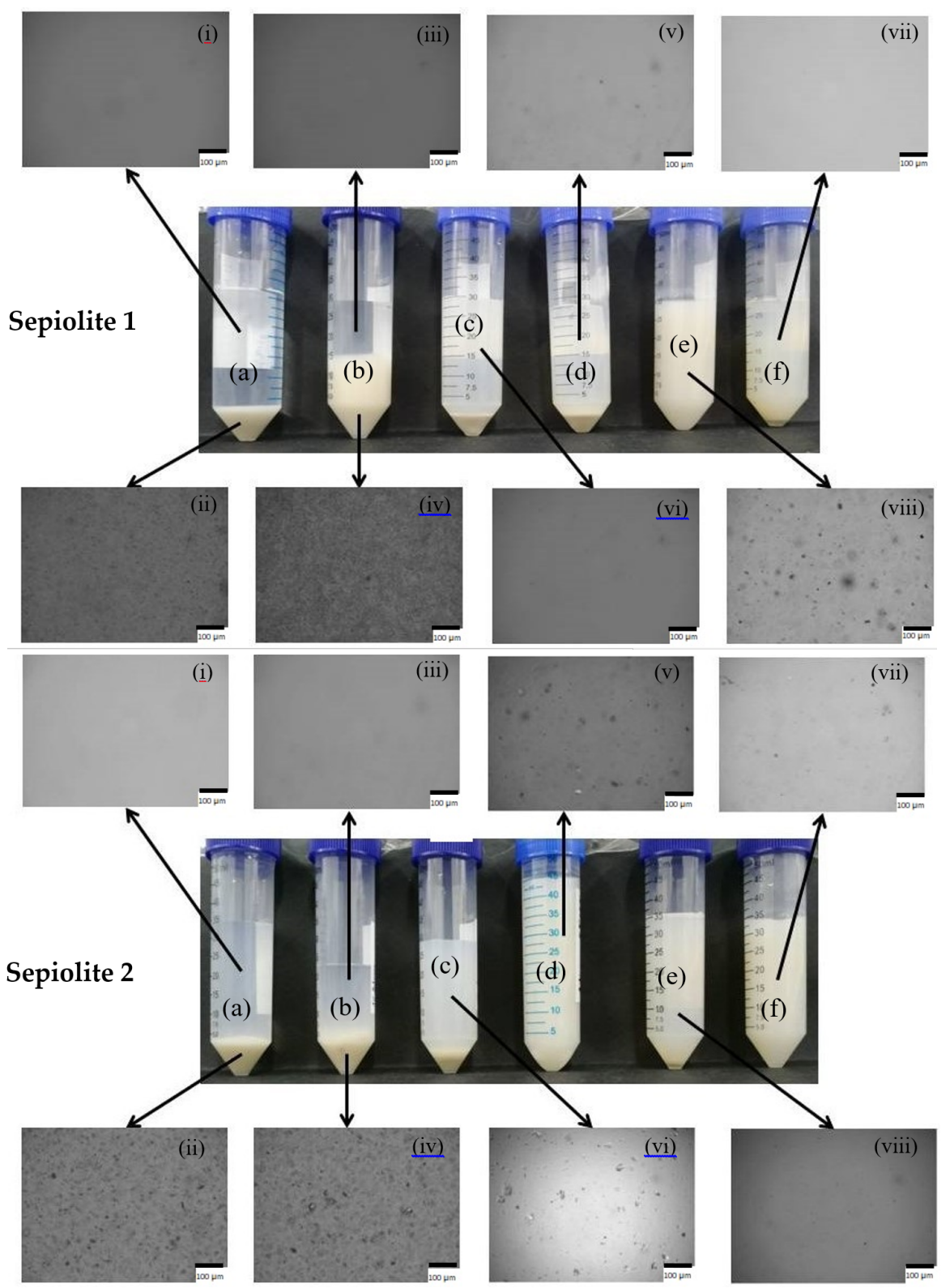

Figure 6. Sepiolite 1 (top) and sepiolite 2 (bottom) $1.0 \mathrm{wt} \%$ aqueous suspensions ( $\mathrm{pH}$ ca. 8). (a) Magnetically stirred; (b) magnetically stirred with $0.1 \mathrm{wt} \%$ polyphosphate; (c) high-shear dispersed; (d) high-shear dispersed with $0.1 \mathrm{wt} \%$ polyphosphate; (e) sonicated; (f) sonicated with $0.1 \mathrm{wt} \%$ polyphosphate. (i) Top phase of suspension (a); (ii) bottom phase of suspension (a); (iii) top phase of suspension (b); (iv) bottom phase of suspension (b); (v) suspension (d); (vi) suspension (c); (vii) suspension (f); (viii) suspension (e). The images (photographs and micrographs) were taken 90 days after sample preparation. The scale bar in the insets (i)-(viii) represent $100 \mu \mathrm{m}$.

Additionally, in the insets, which correspond to microscopic observations of the samples it is also possible to observe clear differences. For the case of sepiolite 1 suspensions prepared using the magnetic stirrer and high-shear disperser, the top phase microscopic image shows a clear image, being the mineral-rich phase concentrated in the bottom of the flask, even when the dispersing agent, polyphosphate, was used (Figure 6, images (i), (iii), (v), and (vi)). On the other hand, for the suspension of sepiolite 2 prepared with the high-shear disperser, the top phase of suspension (c) shows some dispersed particles, and the bottom phase is smaller than the observed for sepiolite 1 . When polyphosphate was added to the suspension of sepiolite 2, using the high-shear disperser, a homogeneous suspension was formed, some particles of relatively large dimensions being observed in 
suspension. Comparing the macroscopic aspect and the microscopic observation of suspensions of sepiolite 2 prepared with the high-speed disperser (Figure 6, samples c and d), it is reasonable to say that part of the mineral was disaggregated into small particles, not visible in the optical microscope, only a small sediment of mineral particles being observed in the absence of polyphosphate.

With ultrasonication, stable suspensions with solely sepiolite in water and also with the addition of polyphosphate (Figure 6, samples e and f) were prepared. However, the sample containing only sepiolite 1 (no dispersant) showed some large particles in suspension, contrary to the samples prepared with sepiolite 1 or sepiolite 2 with dispersing agent, which presented a clear image in the optical microscope. The presence of the dispersing agent can introduce extra charges on the surface of the particles, resulting in an improved disaggregation and stability of the suspensions. Sepiolite 2, without added dispersing agent, already showed a clear image in the microscope, confirming that it is easier to disperse than sepiolite 1 .

\subsubsection{Effect of Mechanical Treatment}

In order to have a better elucidation of the state of the sepiolite aqueous suspensions, dynamic light scattering and zeta potential measurements were performed. The results obtained for the size and zeta potential of the prepared suspensions are shown in Tables 3, 4, A1 and A2 (Appendix A).

As shown in Tables 3 and 4, typically the disaggregation and dispersion stability increase as the power of the dispersion equipment is increased. In the case of sepiolite 1 , for the samples where the magnetic stirrer was employed, only one stable dispersion was obtained (at pH 12 with CMC), contrary to the suspensions prepared using the ultrasonicator where all preparations (excluding the sample with alginate at the initial $\mathrm{pH}$ ) showed stability for a long period of time. The same trend was observed for the sepiolite 2, only three stable suspensions being prepared (at $\mathrm{pH} 12$ ) using the magnetic stirrer, whereas using the ultrasonicator almost all the prepared suspensions (excluding with alginate at pH 3 and 8) were stable. With the high-speed disperser equipment, the results were, in general, intermediate between those above mentioned, being not very effective, as ultrasonication, to generate stable colloidal dispersions of sepiolite. These results are in agreement with previous conclusions from other authors [9].

This factor can be rationalized in the following way: the increase in the power of the dispersing equipment results in higher disaggregation of the clay micro and nanoparticles (aggregates and bundles), leading to particles of smaller size and thus the formation of more stable suspensions.

\subsubsection{Effect of the $\mathrm{pH}$}

An increase in the suspension $\mathrm{pH}$ is expected to improve the dispersibility and colloidal stability of the sepiolite particles, due to an increase in the negative charge of the clay particles (Figure 5). Tables 3, 4, A1 and A2 evidence that the disaggregation and dispersion stability increased with the rise of the suspension $\mathrm{pH}$ from 3 to 12: an increment in the number of stable suspensions, i.e., six suspensions over the 15 investigated at $\mathrm{pH} 3$, to nine suspensions over the 15 investigated at $\mathrm{pH} 12$, was observed when working with sepiolite 1 and from 7 to 12 , over the 15 investigated, in the case of sepiolite 2.

The increase in the negative surface charge of the clay particles is derived from the presence of hydroxyl groups or breakage of $\mathrm{M}-\mathrm{O}-\mathrm{M}(\mathrm{M}=\mathrm{Si}$ or $\mathrm{Mg})$ at highly alkaline $\mathrm{pH}$ [29]. This increase in the surface charge helps the disaggregation and the stabilization of the particles, avoiding also the particle re-aggregation that introduces instability on the systems. Even though no strict defined relationship between zeta potential values and colloidal stability of systems can be assumed, it is known that a very small absolute zeta potential value, lower than $\pm 5.0 \mathrm{mV}$, is a driving force for flocculation and instability of the particles in solution, and only above a value of $\pm 30 \mathrm{mV}$ the systems tend to be stable [30]. Thus, an increase in the absolute value obtained by $\mathrm{pH}$ increment will be favorable to enhance the stability of the suspensions. 
The combination of high $\mathrm{pH}(\mathrm{pH} 12)$ and ultrasonication led to $100 \%$ stable suspensions either for the sepiolite 1 or sepiolite 2. At pH 12 and with the high-shear disperser most of the prepared suspensions were also stable. Even with only magnetic stirring at $\mathrm{pH} 12$, it was possible to obtain a few stable suspensions if an appropriate chemical dispersant (e.g., CMC for both sepiolite samples) was used. These suspensions stayed stable for more than three months, contrary to most of the suspensions at $\mathrm{pH}$ 3. Additionally, the particle size of the suspensions tendentiously decreased with $\mathrm{pH}$ rise and the polydispersity index decreased, indicating a suspension with a narrower distribution of the particle size (Tables 3 and 4). Besides the increase in the surface charge of the clay particles, the dispersing agents used also suffer changes as the $\mathrm{pH}$ is increased, as discussed in the next section.

\subsubsection{Effect of the Dispersants}

The dispersing agents are species able to interact with the clay particles and change some surface properties, leading to an improvement in dispersibility and colloidal stability. In the present work, four different dispersing/stabilizing agents were studied: two synthetic ones, sodium polyphosphate and hydrophobically modified poly(sodium acrylate), and two bio-based ones, sodium carboxymethylcellulose and sodium alginate. It was observed that among all the studied dispersing agents the CMC is the one that provided a higher number of stable dispersions of all the preparations performed, enabling the preparation of stable dispersions in a wide range of conditions. Polyphosphate as chemical dispersant also provided good results in terms of stability of the sepiolite suspensions. However, the particle size of the clay in the CMC stabilized suspensions was tendentiously higher than that obtained when polyphosphate was used, in the cases where it was possible to compare the particle size. On the other hand, poorer results were obtained with alginate, for which the obtained data indicate that this biopolymer is less effective to stabilize sepiolite suspensions in water (under the tested conditions).

The difference in the results obtained with $\mathrm{CMC}$ and alginate can be attributed to a better interaction of the CMC polymer with the clay particles, derived from the relatively low degree of substitution of the cellulose derivative (less charged). The reported values of the pKa for CMC (degree of substitution of 1.2) and alginate are quite similar, ca. 4.6 and 4.5, respectively [31]. It has also been reported that the degree of substitution of CMC affects slightly the pKa value, with a higher substitution by carboxymethyl groups leading to a higher $\mathrm{pKa}$. Thus, being the degree of substitution low (0.7), it is expected that the pKa value of the CMC used in the present work is slightly lower but not significantly different of that of alginate. Additionally, alginate possesses in its structure blocks of guluronate monomers (besides mannuronate) that due to their axial-axial conformation reduce the flexibility of the polymer chain; the mannuronate blocks are more flexible and with a structure similar to CMC structure in its conformation [32]. The lower degree of substitution of CMC (less electrostatic repulsion with the sepiolite fibers), in the one hand, and, on the other hand, its semi-flexible chain leading to a more extended conformation of the polymer chain at low $\mathrm{pH}$ values, can explain the better results obtained when $\mathrm{CMC}$ was used. Moreover, the aggregation and gelation of alginate polymer chains has been reported at $\mathrm{pH}$ values of ca. 3 [33], thus the polymer-polymer interaction being favored instead of polymer-clay interaction, resulting in poor dispersion and stabilization of clay suspension when alginate was used. Finally, it can be hypothesized that CMC is more apt to interact with sepiolite particles, via Van der Waals forces and hydrogen bonds, to produce stable suspensions [34]. 
Table 3. Particle sizes of sepiolite 1 as a function of the different conditions used for preparation of the suspensions.

\begin{tabular}{|c|c|c|c|c|c|c|c|}
\hline & \multirow{2}{*}{ Mechanical Treatment } & \multicolumn{2}{|c|}{ pH 3} & \multicolumn{2}{|c|}{ pH 8} & \multicolumn{2}{|c|}{ pH 12} \\
\hline & & $\operatorname{Di} 50(\mathrm{~nm})$ & PDI & $\operatorname{Di} 50$ (nm) & PDI & $\operatorname{Di} 50$ (nm) & PDI \\
\hline \multirow{2}{*}{ Without dispersing agent } & Magnetic stirring & $2 \varphi$ & - & $2 \varphi$ & - & $2 \varphi$ & - \\
\hline & Ultrasonication & 574 & 0.91 & 782 & 0.29 & 305 & 0.32 \\
\hline \multirow[b]{2}{*}{ With $0.1 \%$ polyphosphate } & Magnetic stirring & $2 \varphi$ & - & $2 \varphi$ & - & $2 \varphi$ & - \\
\hline & High-speed homogenization & $2 \varphi$ & - & $2 \varphi$ & - & $2 \varphi$ & - \\
\hline \multirow[t]{2}{*}{ With $0.1 \%$ polyacrylate } & High-speed homogenization & $2 \varphi$ & - & $2 \varphi$ & - & 1470 & 0.62 \\
\hline & Ultrasonication & 395 & 1.00 & 232 & 0.33 & 485 & 0.36 \\
\hline \multirow{3}{*}{ With $0.1 \%$ CMC } & Magnetic stirring & $2 \varphi$ & - & $2 \varphi$ & - & 1060 & 0.47 \\
\hline & High-speed homogenization & 1170 & 0.27 & 1440 & 0.43 & 791 & 0.42 \\
\hline & Ultrasonication & 691 & 0.29 & 445 & 0.31 & 487 & 0.37 \\
\hline
\end{tabular}

$2 \varphi$-refers to two separate phases. 
Table 4. Particle sizes of sepiolite 2 as a function of the different conditions used for preparation of the suspensions.

\begin{tabular}{|c|c|c|c|c|c|c|c|}
\hline & \multirow{2}{*}{ Mechanical Treatment } & \multicolumn{2}{|c|}{ pH 3} & \multicolumn{2}{|c|}{ pH 8} & \multicolumn{2}{|c|}{ pH 12} \\
\hline & & $\operatorname{Di} 50$ (nm) & PDI & $\operatorname{Di} 50$ (nm) & PDI & $\operatorname{Di} 50$ (nm) & PDI \\
\hline \multirow{3}{*}{ Without dispersing agent } & Magnetic stirring & $2 \varphi$ & - & $2 \varphi$ & - & $2 \varphi$ & - \\
\hline & High-speed homogenization & 389 & 0.75 & 1030 & 0.31 & 757 & 0.32 \\
\hline & Ultrasonication & 508 & 0.91 & 773 & 0.26 & 344 & 0.25 \\
\hline \multirow{3}{*}{ With $0.1 \%$ polyphosphate } & Magnetic stirring & $2 \varphi$ & - & $2 \varphi$ & - & 350 & 0.28 \\
\hline & High-speed homogenization & 794 & 0.28 & 385 & 0.27 & 418 & 0.25 \\
\hline & Ultrasonication & 379 & 0.26 & 253 & 0.25 & 257 & 0.25 \\
\hline \multirow{3}{*}{ With $0.1 \%$ polyacrylate } & Magnetic stirring & $2 \varphi$ & - & $2 \varphi$ & - & 320 & 0.46 \\
\hline & High-speed homogenization & 2500 & 0.49 & 372 & 0.42 & $2 \varphi$ & - \\
\hline & Ultrasonication & 1760 & 0.42 & 578 & 0.62 & 499 & 0.29 \\
\hline \multirow{3}{*}{ With $0.1 \%$ CMC } & Magnetic stirring & $2 \varphi$ & - & $2 \varphi$ & - & 1030 & 0.52 \\
\hline & High-speed homogenization & $2 \varphi$ & - & 1370 & 0.50 & 1120 & 0.53 \\
\hline & Ultrasonication & 620 & 0.38 & 551 & 0.34 & 485 & 0.32 \\
\hline \multirow{3}{*}{ With $0.1 \%$ alginate } & Magnetic stirring & $2 \varphi$ & - & $2 \varphi$ & - & $2 \varphi$ & - \\
\hline & High-speed homogenization & $2 \varphi$ & - & $2 \varphi$ & - & 558 & 0.41 \\
\hline & Ultrasonication & $2 \varphi$ & - & $2 \varphi$ & - & 401 & 0.31 \\
\hline
\end{tabular}

$2 \varphi$-refers to two separate phases. 
From the synthetic options studied, polyphosphate demonstrated to be the more effective, presenting better results than $\mathrm{CMC}$ in the case of sepiolite 2, but worse results in the case of sepiolite 1 . Polyphosphate has a very low $\mathrm{pKa}$ value, being ionized and negatively charged in the entire range of studied $\mathrm{pH}$ [35]. It was expected that this compound could act as a good dispersing/stabilizing agent in the studied range. It is important to highlight that phosphates are traditionally used as dispersing agents for clay suspensions [36]. However, for sepiolite 1, it seems that the highly negative charge density of the polyphoshate did not favor the interaction with the clay, unless ultrasonication is applied in the system. For sepiolite 2, particularly at low $\mathrm{pH}$, the results with polyphosphate were even better than the obtained when CMC was used. This observation reveals a better interaction of phosphate anions with the low charged clay particles at low $\mathrm{pH}$.

The results obtained for polyacrylate (HM-PAA) as dispersant and stabilizer were quite unexpected. It was found that this polymer can have a good performance acting as disperser of sepiolite, being less effective as stabilizer of the suspensions. These results can be explained by two factors: the pKa of the polymer is higher than that of the other three dispersing agents studied, ca. 5.8 [31]; secondly, the polymer possesses hydrophobic modification, which leads to a shift in the expansion of the polymer chain [37]. These two factors can explain the poor stabilization effect observed for low $\mathrm{pH}$ values, having been typically observed suspension gelation with time, and a slightly better performance at $\mathrm{pH} 12$, where the polymer is fully ionized and extended, being able to interact and stabilize the clay particles. It is important however to note that the lowest particle size obtained for the sonicated sepiolite 1 suspensions was obtained using HM-PAA at $\mathrm{pH} 8$, with a particle size value of ca. 230 $\mathrm{nm}$. This can be attributed to the excellent affinity of this kind of polymer, amphiphilic polymers, to interact for instance with surfactants [38] and other compounds containing both hydrophilic and hydrophobic domains, as is the case of the sepiolite clays $[6,39,40]$. In summary, the combination of an adequate dispersing agent with suitable dispersing equipment and suspension $\mathrm{pH}$ led to a significant improvement in disaggregation, dispersion, and stability of sepiolite suspensions in aqueous medium.

\section{Conclusions}

The present work explored the effect of different dispersing equipment and chemical dispersing agents on the dispersion state and stability of sepiolite suspensions. Two different samples of sepiolite, obtained from different physical pre-treatments, were studied. The characterization results of the sepiolite samples in the solid state revealed the characteristic magnesium silicate nature and high purity of the raw materials and clearly confirmed their fibrous-like structure. Additionally, the isoelectric point, ca. 3.2 for sepiolite 1 and ca. 2.5 for sepiolite 2, determined by zeta potential measurements, was in good agreement with other values reported in literature. Our results put in evidence the importance of the dispersing conditions used in order to prepare stable dispersions of sepiolite. It was observed that the use of high-energy dispersing apparatus, as the ultrasonicator, produced more stable suspensions compared to low-energy equipment, like the magnetic stirrer. On the other hand, it was observed that the biopolymer CMC showed a higher ability to produce stable suspensions; however, tendentiously, the smaller particle size was obtained when polyphosphate was used. Amphiphilic polymers, such as HM-PAA, also demonstrated good ability to disperse sepiolite particles, due to their good ability to interact with species containing hydrophobic moieties and reduce the Van der Waals forces among the clay rods. Nevertheless, most of the prepared suspensions with HM-PAA at low $\mathrm{pH}$, tended to form viscous gels with time, ruling out the possibility of using this synthetic polymer to stabilize sepiolite, at least under the tested conditions. In sum, the combination of a high energy dispersing equipment with an appropriate dispersing agent led to stable suspensions with optimal properties to be used in different applications, like composites.

Author Contributions: Conceptualization-L.A. and J.A.F.G.; investigation-L.A. and J.A.F.G.; methodology-L.A.; writing-original draft-L.A., E.F. and J.A.F.G.; review and editing-L.A., E.F., J.S., M.G.R. and J.A.F.G.; bibliographic search-J.A.F.G. and E.F.; funding acquisition-M.G.R. and J.A.F.G.; project administration-J.A.F.G. All authors have read and agreed to the published version of the manuscript. 
Funding: The present research was supported by the R \& D Project "FILCNF-New generation of composite films of cellulose nanofibrils with mineral particles as high strength materials with gas barrier properties" (PTDC/QUI-OUT/31884/2017, CENTRO 01-0145-FEDER-031884), Strategic Research Centre Project UIDB00102/2020 and Techn \& Art (UID/05488/2018) funded by the Fundação para a Ciência e Tecnologia (FCT).

Acknowledgments: The authors acknowledge Luís Maria, Eirini Potsi, and Solange Magalhães for the help in the preparation of a few suspensions, particle size and zeta potential measurements.

Conflicts of Interest: The authors declare no conflict of interest. 


\section{Appendix A}

Table A1. Zeta potential values for sepiolite 1 suspensions as a function of the different conditions used.

\begin{tabular}{|c|c|c|c|c|c|c|c|}
\hline & \multirow[b]{2}{*}{ Mechanical Treatment } & \multicolumn{2}{|c|}{$\mathrm{pH} 3$} & \multicolumn{2}{|c|}{$\mathrm{pH} 8$} & \multicolumn{2}{|c|}{ pH 12} \\
\hline & & $\begin{array}{c}\text { Zeta Potential } \\
(\mathrm{mV})\end{array}$ & $\begin{array}{c}\text { Zeta } \\
\text { Deviation }\end{array}$ & $\begin{array}{c}\text { Zeta Potential } \\
(\mathrm{mV})\end{array}$ & $\begin{array}{c}\text { Zeta } \\
\text { Deviation }\end{array}$ & $\begin{array}{l}\text { Zeta Potential } \\
(\mathrm{mV})\end{array}$ & $\begin{array}{c}\text { Zeta } \\
\text { Deviation }\end{array}$ \\
\hline \multirow{3}{*}{$\begin{array}{c}\text { Without } \\
\text { dispersing agent }\end{array}$} & \multirow{3}{*}{$\begin{array}{l}\text { Magnetic stirring } \\
\text { High-speed } \\
\text { homogenization } \\
\text { Ultrasonication }\end{array}$} & $2 \varphi$ & - & $2 \varphi$ & - & $2 \varphi$ & - \\
\hline & & $2 \varphi$ & - & $2 \varphi$ & - & -30 & 3.4 \\
\hline & & -19 & 4.3 & -19 & 4.0 & -48 & 9.6 \\
\hline \multirow{3}{*}{$\begin{array}{c}\text { With } 0.1 \% \\
\text { polyphosphate }\end{array}$} & \multirow{3}{*}{$\begin{array}{l}\text { Magnetic stirring } \\
\text { High-speed } \\
\text { homogenization } \\
\text { Ultrasonication }\end{array}$} & $2 \varphi$ & - & $2 \varphi$ & - & $2 \varphi$ & - \\
\hline & & $2 \varphi$ & - & $2 \varphi$ & - & $2 \varphi$ & - \\
\hline & & -43 & 6.8 & -57 & 8.9 & -52 & 10.4 \\
\hline \multirow{3}{*}{$\begin{array}{l}\text { With } 0.1 \% \\
\text { polyacrylate }\end{array}$} & \multirow{3}{*}{$\begin{array}{l}\text { Magnetic stirring } \\
\text { High-speed } \\
\text { homogenization } \\
\text { Ultrasonication }\end{array}$} & $2 \varphi$ & - & $2 \varphi$ & - & $2 \varphi$ & - \\
\hline & & $2 \varphi$ & - & $2 \varphi$ & - & -49 & 4.9 \\
\hline & & -22 & 3.1 & -26 & 5.6 & -52 & 5.0 \\
\hline \multirow{3}{*}{ With $0.1 \%$ CMC } & \multirow{3}{*}{$\begin{array}{c}\text { Magnetic stirring } \\
\text { High-speed } \\
\text { homogenization } \\
\text { Ultrasonication }\end{array}$} & $2 \varphi$ & - & $2 \varphi$ & - & -56 & 3.9 \\
\hline & & -38 & 3.1 & -62 & 4.5 & -50 & 3.8 \\
\hline & & -36 & 3.3 & -54 & 4.4 & -51 & 5.5 \\
\hline \multirow{3}{*}{ With $0.1 \%$ alginate } & \multirow{3}{*}{$\begin{array}{c}\text { Magnetic stirring } \\
\text { High-speed } \\
\text { homogenization } \\
\text { Ultrasonication }\end{array}$} & $2 \varphi$ & - & $2 \varphi$ & - & $2 \varphi$ & - \\
\hline & & $2 \varphi$ & - & $2 \varphi$ & - & $2 \varphi$ & - \\
\hline & & -41 & 3.8 & $2 \varphi$ & - & -56 & 8.7 \\
\hline
\end{tabular}

$2 \varphi$-refers to two separate phases. Zeta deviation is the uncertainty of the zeta potential determination. 
Table A2. Zeta potential values for sepiolite 2 suspensions as a function of the different conditions used.

\begin{tabular}{|c|c|c|c|c|c|c|c|}
\hline & \multirow[b]{2}{*}{ Mechanical Treatment } & \multicolumn{2}{|c|}{ pH 3} & \multicolumn{2}{|c|}{ pH 8} & \multicolumn{2}{|c|}{ pH 12} \\
\hline & & $\begin{array}{l}\text { Zeta Potential } \\
(\mathrm{mV})\end{array}$ & $\begin{array}{c}\text { Zeta } \\
\text { Deviation }\end{array}$ & $\begin{array}{l}\text { Zeta Potential } \\
(\mathrm{mV})\end{array}$ & $\begin{array}{c}\text { Zeta } \\
\text { Deviation }\end{array}$ & $\begin{array}{l}\text { Zeta Potential } \\
(\mathrm{mV})\end{array}$ & $\begin{array}{c}\text { Zeta } \\
\text { Deviation }\end{array}$ \\
\hline \multirow{3}{*}{$\begin{array}{c}\text { Without } \\
\text { dispersing agent }\end{array}$} & Magnetic stirring & $2 \varphi$ & - & $2 \varphi$ & - & $2 \varphi$ & - \\
\hline & $\begin{array}{c}\text { High-speed } \\
\text { homogenization }\end{array}$ & -19 & 3.1 & -22 & 4.9 & -38 & 6.0 \\
\hline & Ultrasonication & -19 & 2.7 & -25 & 8.4 & -47 & 8.4 \\
\hline \multirow{3}{*}{$\begin{array}{c}\text { With } 0.1 \% \\
\text { polyphosphate }\end{array}$} & Magnetic stirring & $2 \varphi$ & - & $2 \varphi$ & - & -54 & 8.8 \\
\hline & $\begin{array}{c}\text { High-speed } \\
\text { homogenization }\end{array}$ & -38 & 5.3 & -60 & 10.3 & -55 & 10.0 \\
\hline & Ultrasonication & -38 & 5.5 & -58 & 11.6 & -54 & 11.4 \\
\hline \multirow{3}{*}{$\begin{array}{l}\text { With } 0.1 \% \\
\text { polyacrylate }\end{array}$} & Magnetic stirring & $2 \varphi$ & - & $2 \varphi$ & - & -53 & 4.7 \\
\hline & $\begin{array}{c}\text { High-speed } \\
\text { homogenization }\end{array}$ & -21 & 2.8 & -24 & 4.7 & $2 \varphi$ & - \\
\hline & Ultrasonication & -24 & 5.2 & -29 & 3.5 & -56 & 5.1 \\
\hline \multirow{3}{*}{ With $0.1 \%$ CMC } & Magnetic stirring & $2 \varphi$ & - & $2 \varphi$ & - & -65 & 4.6 \\
\hline & $\begin{array}{c}\text { High-speed } \\
\text { homogenization }\end{array}$ & $2 \varphi$ & - & -60 & 4.4 & -54 & 4.3 \\
\hline & Ultrasonication & -50 & 4.5 & -66 & 5.4 & -57 & 5.0 \\
\hline \multirow{3}{*}{ With $0.1 \%$ alginate } & Magnetic stirring & $2 \varphi$ & - & $2 \varphi$ & - & $2 \varphi$ & - \\
\hline & $\begin{array}{c}\text { High-speed } \\
\text { homogenization }\end{array}$ & $2 \varphi$ & - & $2 \varphi$ & - & -55 & 4.9 \\
\hline & Ultrasonication & $2 \varphi$ & - & $2 \varphi$ & - & -52 & 9.1 \\
\hline
\end{tabular}

$2 \varphi-$ refers to two separate phases. Zeta deviation is the uncertainty of the zeta potential determination. 


\section{References}

1. Singer, A. Palygorskite and Sepiolite Group Minerals. In Minerals in Soil Environments, 2nd ed.; Dixon, J.B., Weed, S.B., Eds.; Soil Science Society of America: Madison, WI, USA, 1989; Volume 1, pp. 829-872.

2. Guggenheim, S.; Krekeler, M.P.S. Chapter 1-The Structures and Microtextures of the Palygorskite-Sepiolite Group Minerals. In Developments in Clay Science; Galàn, E., Singer, A., Eds.; Elsevier: Amsterdam, The Netherlands, 2011; Volume 3, pp. 3-32.

3. Galan, E. Properties and applications of palygorskite-sepiolite clays. Clay Miner. 1996, 31, 443-453. [CrossRef]

4. Ruiz-Hitzky, E.; Darder, M.; Fernandes, F.M.; Wicklein, B.; Alcântara, A.C.S.; Aranda, P. Fibrous clays based bionanocomposites. Prog. Polym. Sci. 2013, 38, 1392-1414. [CrossRef]

5. Alves, L.; Ferraz, E.; Gamelas, J.A.F. Composites of nanofibrillated cellulose with clay minerals: A review. Adv. Colloid Interface Sci. 2019, 272, 101994. [CrossRef] [PubMed]

6. Wang, A.; Wang, W. 1-Introduction. In Nanomaterials from Clay Minerals; Wang, A., Wang, W., Eds.; Elsevier: Amsterdam, The Netherlands, 2019; pp. 1-20. [CrossRef]

7. Küncek, İ.; Şener, S. Adsorption of methylene blue onto sonicated sepiolite from aqueous solutions. Ultrason. Sonochem. 2010, 17, 250-257. [CrossRef]

8. Lo Dico, G.; Wicklein, B.; Lisuzzo, L.; Lazzara, G.; Aranda, P.; Ruiz-Hitzky, E. Multicomponent bionanocomposites based on clay nanoarchitectures for electrochemical devices. Beilstein J. Nanotechnol. 2019, 10, 1303-1315. [CrossRef]

9. Perez-Carvajal, J.; Aranda, P.; Ruiz-Hitzky, E. Titanosilicate-sepiolite hybrid nanoarchitectures for hydrogen technologies applications. J. Solid State Chem. 2019, 270, 287-294. [CrossRef]

10. Viseras, C.; Meeten, G.H.; Lopez-Galindo, A. Pharmaceutical grade phyllosilicate dispersions: The influence of shear history on floc structure. Int. J. Pharm. 1999, 182, 7-20. [CrossRef]

11. Xu, J.; Zhang, J.; Wang, Q.; Wang, A. Disaggregation of palygorskite crystal bundles via high-pressure homogenization. Appl. Clay Sci. 2011, 54, 118-123. [CrossRef]

12. Takei, T.; Oda, R.; Miura, A.; Kumada, N.; Kinomura, N.; Ohki, R.; Koshiyama, H. Effect of dispersion of sepiolite in sepiolite-NBR composite on the tensile strength. Compos. Part B Eng. 2013, 44, 260-265. [CrossRef]

13. De Lima, J.A.; Camilo, F.F.; Faez, R.; Cruz, S.A. A new approch to sepiolite dispersion by treatment with ionic liquids. Appl. Clay Sci. 2017, 143, 234-240. [CrossRef]

14. García, N.; Guzmán, J.; Benito, E.; Esteban-Cubillo, A.; Aguilar, E.; Santarén, J.; Tiemblo, P. Surface Modification of Sepiolite in Aqueous Gels by Using Methoxysilanes and Its Impact on the Nanofiber Dispersion Ability. Langmuir 2011, 27, 3952-3959. [CrossRef]

15. Santiago, F.; Mucientes, A.E.; Osorio, M.; Poblete, F.J. Synthesis and swelling behaviour of poly (sodium acrylate)/sepiolite superabsorbent composites and nanocomposites. Polym. Int. 2006, 55, 843-848. [CrossRef]

16. Alcântara, A.C.S.; Darder, M.; Aranda, P.; Ayral, A.; Ruiz-Hitzky, E. Bionanocomposites based on polysaccharides and fibrous clays for packaging applications. J. Appl. Polym. Sci. 2016, 133, 42362. [CrossRef]

17. Darder, M.; Matos, C.R.S.; Aranda, P.; Gouveia, R.F.; Ruiz-Hitzky, E. Bionanocomposite foams based on the assembly of starch and alginate with sepiolite fibrous clay. Carbohydr. Polym. 2017, 157, 1933-1939. [CrossRef]

18. González del Campo, M.M.; Darder, M.; Aranda, P.; Akkari, M.; Huttel, Y.; Mayoral, A.; Bettini, J.; Ruiz-Hitzky, E. Functional Hybrid Nanopaper by Assembling Nanofibers of Cellulose and Sepiolite. Adv. Funct. Mater. 2018, 28, 1703048. [CrossRef]

19. Alvarez Berenguer, A.; Perez Castells, R.; Aragon Martinez, J.J.; Esteban Aldezabal, M.A. A rheological grade sepiolite product and processes for its manufacture. Langmuir 1990, 27, 3952-3959.

20. Sabah, E.; Mart, U.; Çınar, M.; Çelik, M.S. Zeta Potentials of Sepiolite Suspensions in Concentrated Monovalent Electrolytes. Sep. Sci. Technol. 2007, 42, 2275-2288. [CrossRef]

21. Frost, R.L.; Ding, Z. Controlled rate thermal analysis and differential scanning calorimetry of sepiolites and palygorskites. Thermochim. Acta 2003, 397, 119-128. [CrossRef]

22. Frost, R.L.; Kristóf, J.; Horváth, E. Controlled rate thermal analysis of sepiolite. J. Therm. Anal. Calorim. 2009, 98, 423-428. [CrossRef] 
23. Nagata, H.; Shimoda, S.; Sudo, T. On Dehydration of Bound Water of Sepiolite. Clays Clay Mineral. 1974, 22, 285-293. [CrossRef]

24. Post, J.E.; Bish, D.L.; Heaney, P.J. Synchrotron powder X-ray diffraction study of the structure and dehydration behavior of sepiolite. Am. Mineral. 2007, 92, 91-97. [CrossRef]

25. Frost, R.L.; Locos, O.B.; Ruan, H.; Kloprogge, J.T. Near-infrared and mid-infrared spectroscopic study of sepiolites and palygorskites. Vib. Spectrosc. 2001, 27, 1-13. [CrossRef]

26. Farmer, V.C. The Infrared Spectra of Minerals; Mineralogical Society of Great Britain and Ireland: London, UK, 1974; Volume 4.

27. Dikmen, S.; Yilmaz, G.; Yorukogullari, E.; Korkmaz, E. Zeta potential study of natural- and acid-activated sepiolites in electrolyte solutions. Can. J. Chem. Eng. 2012, 90, 785-792. [CrossRef]

28. Alkan, M.; Demirbaş, Ö.; Doğan, M. Electrokinetic properties of sepiolite suspensions in different electrolyte media. J. Colloid Interface Sci. 2005, 281, 240-248. [CrossRef]

29. Wang, W.; Wang, A. Recent progress in dispersion of palygorskite crystal bundles for nanocomposites. Appl. Clay Sci. 2016, 119, 18-30. [CrossRef]

30. Salopek, B.; Krasić, D.; Filipović, S. Measurement and application of zeta-potential. Rud. Geol. Naft. Zb. 1992, 4, 147-151.

31. Vleugels, L.F.W.; Ricois, S.; Voets, I.K.; Tuinier, R. Determination of the 'apparent pKa' of selected food hydrocolloids using ortho-toluidine blue. Food Hydrocoll. 2018, 81, 273-283. [CrossRef]

32. Kakita, H.; Kamishima, H. Some properties of alginate gels derived from algal sodium alginate. J. Appl. Phycol. 2008, 20, 543-549. [CrossRef]

33. Andriamanantoanina, H.; Rinaudo, M. Relationship between the molecular structure of alginates and their gelation in acidic conditions. Polym. Int. 2010, 59, 1531-1541. [CrossRef]

34. Alves, L.; Medronho, B.F.; Antunes, F.E.; Romano, A.; Miguel, M.G.; Lindman, B. On the role of hydrophobic interactions in cellulose dissolution and regeneration: Colloidal aggregates and molecular solutions. Colloids Surf. A: Physicochem. Eng. Asp. 2015, 483, 257-263. [CrossRef]

35. Younes, M.; Aquilina, G.; Castle, L.; Engel, K.-H.; Fowler, P.; Frutos Fernandez, M.J.; Fürst, P.; Gürtler, R.; Husøy, T.; Mennes, W.; et al. Re-evaluation of phosphoric acid-phosphates-di-, tri- and polyphosphates (E 338-341, E 343, E 450-452) as food additives and the safety of proposed extension of use. EFSA J. 2019, 17, 5674. [CrossRef]

36. Suman, K.; Mittal, M.; Joshi, Y.M. Effect of sodium pyrophosphate and understanding microstructure of aqueous LAPONITE ${ }^{\circledR}$ dispersion using dissolution study. J. Phys. Condens. Matter 2020, 32, 224002. [CrossRef] [PubMed]

37. Alves, L.; Lindman, B.; Klotz, B.; Böttcher, A.; Haake, H.-M.; Antunes, F.E. Rheology of polyacrylate systems depends strongly on architecture. Colloid Polym. Sci. 2015, 293, 3285-3293. [CrossRef]

38. Alves, L.; Lindman, B.; Klotz, B.; Böttcher, A.; Haake, H.-M.; Antunes, F.E. On the rheology of mixed systems of hydrophobically modified polyacrylate microgels and surfactants: Role of the surfactant architecture. J. Colloid Interface Sci. 2018, 513, 489-496. [CrossRef] [PubMed]

39. Alvarado, M.; Chianelli, R.C.; Arrowood, R.M. Computational Study of the Structure of a Sepiolite/Thioindigo Mayan Pigment. Bioinorg. Chem. Appl. 2012, 2012, 672562. [CrossRef]

40. Benli, B.; Du, H.; Celik, M.S. The anisotropic characteristics of natural fibrous sepiolite as revealed by contact angle, surface free energy, AFM and molecular dynamics simulation. Colloids Surf. A: Physicochem. Eng. Asp. 2012, 408, 22-31. [CrossRef]

(C) 2020 by the authors. Licensee MDPI, Basel, Switzerland. This article is an open access article distributed under the terms and conditions of the Creative Commons Attribution (CC BY) license (http://creativecommons.org/licenses/by/4.0/). 